\title{
0 espiritismo brasileiro: Uma produção discursiva
}

Francisco Jomário Pereira (UEPB)*

https://orcid.org/0000-0003-1778-9207

\section{Resumo:}

Este trabalho tem por finalidade analisar a constituição do espiritismo brasileiro enquanto doutrina e religião, a partir dos discursos internos produzidos por doutrinadores espíritas. Para tal, fazemos uso da análise do discurso aliado à Sociologia da Religião. Compartilhamos da ideia de que o discurso não é apenas uma configuração linguística, devendo ser lido e interpretado a partir do contexto histórico e cultural. Observamos que os discursos adotados a partir da chegada da doutrina em solo brasileiro divergem do discurso francês baseado no positivismo e no iluminismo. Assim, sua formatação torna-se diferente da pensada por Kardec no século XIX. Desse modo, concluímos que no Brasil predominou o aspecto religioso e personalista em detrimento do científico.

Palavras chave: Análise do Discurso; Espiritismo; Sociologia da Religião.

\section{Abstract:}

\section{Brazilian Spiritism: A discursive production}

This paper mains to analyze the Brazilian spiritism constitution as doctrine and religion, based on the internal speeches, produced by spiritist indoctrinators. For that, we use critical discourse analysis associated with the Sociology of Religion. We share the idea that the discourse is not just a linguistic configuration, and should be read and interpreted from the historical and cultural context. We observed that the discourses adopted from the arrival of the doctrine on Brazilian soil diverge from the French discourse based on positivism and enlightenment, so its formatting becomes different from what Kardec thought in the 19th century. Therefore, in Brazil predominated the religious and personalist aspect instead of the scientific.

Keywords: Discourse Analysis; Spiritism; Sociology of Religion.

* Doutor em Sociologia - UFPB. Professor no Departamento de Ciências Sociais - UEPB.

E-mail: jomariocp@gmail.com / jomario@servidor.uepb.edu.br 


\section{Introdução}

Tudo que produz sentido para alguém, é discurso. Não se produz discurso de forma livre, é sempre controlado. (Rosário Gregolin, 2006).

O que é o discurso? Como ele é produzido? Quem o produz, onde ele pode ser registrado, salvo, reproduzido? São inúmeras perguntas que surgiram e motivaram este trabalho. Buscamos responde-las ao longo do texto. Este trabalho desponta de questões pessoais intrínsecas ao aspecto religioso. 0 desejo de analisar o discurso espírita emerge a partir do momento em que observamos silêncios sobre determinado tema, enveredando mais e mais pela doutrina e pelos estudos acadêmicos, desaguando, em partes, no texto que se apresenta.

0 primeiro contato que tive com o espiritismo foi por meio de romances espíritas, trazidos por uma tia que reside no estado de São Paulo, que foi passar férias em minha cidade natal. Esse fato ocorreu aproximadamente há quinze anos. Em sua bagagem trouxera exemplares de romances psicografados pela médium Zibia Gaspareto. Esse primeiro contato foi profícuo, pois o interesse pela literatura espírita só aumentou. Segui pela doutrina e me tornei espírita.

Começamos a ler os livros do Pentateuco espírita $^{1}$, a frequentar as palestras públicas e a tomar os passes magnéticos. Então, me auto denominei espírita, me reconheci e me senti pertencente a uma religião.

Ao passo que seguia com os estudos doutrinários, aprofundávamos os estudos nas Ciências Sociais, ao ponto de tornar a doutrina espírita nosso objeto de pesquisa. Assim, segui pela análise do discurso espí-

1 É composto pelos livros: dos Espíritos, dos Médiuns, o Evangelho Segundo o Espiritismo, 0 Céu e 0 Inferno e, por fim, a Gênesis. Esses são os livros base do espiritismo. rita brasileiro. Nosso corpus de análise, de modo amplo, correspondeu aos discursos oficiais proferidos pela Federação Espírita Brasileira, livros codificados por Kardec, discursos de médiuns e intelectuais espíritas, principalmente Chico Xavier e Divaldo Pereira Franco, e por fim, entrevistas de espíritas, com longa carreira na doutrina, refletindo sobre o que é a doutrina.

Observamos uma série de mudanças e diferenças entre o espiritismo brasileiro e o modelo francês. A partir dessa constatação, introduzimos nosso assunto, o processo de reconfiguração do Espiritismo francês em solo brasileiro e o formato que tomou ao chegar ao Brasil. Sua forma foi moldada a partir dos embates teóricos e discursivos entre os primeiros médiuns e intelectuais espíritas brasileiros, chegando a um "consenso" apenas na década de 40 do século XX.

Assim, nos propomos a analisar a produção discursiva a respeito do espiritismo, buscando compreender o surgimento e consolidação da doutrina espírita enquanto religião e sua institucionalização em solo brasileiro.

\section{Análise do Discurso, concepções e conceitos}

Muito se discute a respeito do conceito de Análise do Discurso - AD, pois, enquanto metodologia de análise, não se restringe apenas a área linguística. A História, Antropologia e a Sociologia também utilizam a AD como ferramenta analítica. Dois nomes se destacam enquanto referência teórica: Michel Foucault e Michel Pêcheux. Ambos são expoentes dessa nova forma de pensar, estudar e analisar o discurso, os sujeitos produtores e a reverberação de seus acontecimentos. 
Devemos, pois, explicitar que o emprego da $\mathrm{AD}$ não é particularidade do campo linguístico, não é pelo fato de trazer em seu cerne o termo 'discurso' que ficará recluso ao campo das letras, linguística ou da gramática.

A análise do Discurso, tendo o discurso como objeto de investigação, trabalha com a linguagem sob suas diferentes possibilidades de existência, e a considera em uma relação direta com a história- esta como o que determina as possibilidades de realização daquela- e com os sujeitos. 0 discurso é exterior à língua, mas depende dela para sua possibilidade de existência material, ou seja, o discurso materializa-se em forma de texto, de imagens, sob determinações históricas. (FERNANDES, 2012, p. 16)

Justamente por não ser exclusividade da linguística (NOGUEIRA, 2001), a AD é muitas vezes criticada por carecer de uma identidade própria, considerada apenas repetições e banalizações, afirmativas que Maria do Rosário Gregolin (2006) rebate com veemência. Gregolin (2006) nos faz refletir sobre as influências marxistas, freudianas, althusserianas e estruturalistas no desenvolvimento das Ciências Humanas nas décadas de 1960 a 1980, especialmente sobre os conflitos e discussões entre Pêcheux e Foucault entorno da AD que perdura até os dias atuais.

De forma breve poderíamos afirmar que a AD é uma forma de analisar a história enquanto produto do discurso, este sob determinas condições políticas, filosóficas e ideológicas.

Por ser usada em diversos campos e áreas, a $\mathrm{AD}$ não terá uma definição única, "existem várias, desde orientações mais linguísticas até mais psicossociológicas, e nenhuma pretende ser absolutamente definitiva" (NOGUEIRA, 2001, p. 22), seria impossível conter todas as variedades teóricas e práticas que podem ser conceituadas por
Análise do Discurso. Buscando aprofundar e delimitar melhor uma proposta do conceito de $\mathrm{AD}$, iremos nos ater a Foucault e sua produção, usando como ponto de partida o seu texto em ocasião da Aula Inaugural no Collège de France em 02 de dezembro de 1970, A Ordem do Discurso.

Escolhemos esse texto ou se preferir momento, por marcar a transição entre dois momentos da produção de Foucault. 0 primeiro seria o momento arqueológico (As Palavras e as Coisas, 1966, e Arqueologia do Saber, 1969), onde voltou-se para a história da loucura, medicina e dos campos dos saberes, "tratara-se, nesse momento, de investigar os saberes que embasaram a cultura ocidental, de buscar o método arqueológico para entender a história desses saberes" (GREGOLIN, 2006, p. 55). 0 segundo é A Ordem do Discurso (1970).

Na primeira fase, ele nos apresenta conceitos importantes que ajudaram a definir a sua perspectiva de $\mathrm{AD}$, como por exemplo acontecimento discursivo, enunciado, formação discursiva, que implicaram no conceito de discurso. Este sendo compreendido como,

um conjunto de enunciados, na medida em que se apoiem na mesma formação discursiva; [...] é constituído de um número limitado de enunciados para os quais podemos definir um conjunto de condições de existência; [...] é, de parte a parte, histórico - fragmento de história, unidade e descontinuidade na própria história, que coloca o problema de seus próprios limites, de seus cortes, de suas transformações, dos modos específicos de sua temporalidade, e não de seu surgimento abrupto em meio às cumplicidades do tempo. (FOUCAULT, 2008, p. 133)

Observamos que, no primeiro momento existe a busca pela ruptura, descontinuidade, transformação, pois, Foucault crê que o discurso é prática, ação, não algo estático, 
contínuo, linear, como se observa na noção tradicional de História. Assim, Foucault nos apresenta uma nova perspectiva e definição, como sendo "um conjunto de regras anônimas, históricas, sempre determinadas no tempo e no espaço, que definiram, em uma dada época e para uma determinada área social, econômica, geográfica ou linguística, as condições de exercício da função enunciativa". (idem, p. 133).

Depois de A Ordem do Discurso de 1970, Foucault percorre outros dois momentos de produção, o segundo, focado nas práticas divergentes, empreende a análise das articulações entre saberes e os poderes, traçando uma genealogia do poder, (Vigiar e Punir, 1975, e Microfísica do Poder, 1979), já em um terceiro momento, "ele investigou a subjetivação a partir de técnicas de si, [...] do governo de si e dos outros, orientando suas pesquisas na direção da sexualidade, da constituição histórica de uma ética e estética de si (História da sexualidade, em três volumes, 1976, 1984, 1984)" (GREGOLIN, 2006 p. 55). Temos que ressaltar que, as fases mencionadas não são estanques e separadas, elas se complementam e se reconfiguram.

Pensando a construção teórica da AD por Foucault, nos ateremos a análise dos discursos espíritas, sendo analisados a partir da concepção teórica foucaultiana, assim, buscamos compreender quem produz, como produz e quais os efeitos dos discursos. Para tal empreitada, apresentaremos, de forma breve, o histórico do surgimento da doutrina, bem como a sua chegada ao Brasil.

\section{Historicizando}

Conforme registros históricos, o surgimento do Espiritismo data do século XIX na França, de modo que fenômenos inexplicáveis começaram a movimentar a Europa, mesas giratórias e "inteligentes" chamaram atenção do até então Hippolyte Leon Denizard Rivail, que adotaria posteriormente o pseudônimo de Allan Kardec, tornando-se o codificador da doutrina que viria a florescer e a ganhar espaço no Brasil (ARRIBAS, 2017, 2014; GIUMBELLI, 1995).

Nesse diapasão, observa-se as bases da doutrina, razão iluminista e positivista, sempre em contraposição ao declínio vivido pelas religiões cristãs. Nessa perspectiva, Lewgoy (2008 p. 85) argumenta que "Allan Kardec, o criador do espiritismo, encarnou como poucos o ideal racionalista do século XIX, quando a ciência, a filosofia da história e o determinismo passaram a tomar o lugar do voluntarismo subjetivo na imaginação moral".

A partir desse contexto, surgem as obras que inauguram e servem de base moral e espiritual da doutrina Espírita, reunidas no Pentateuco Espírita - O Livro dos Espíritos, O Livro dos Médiuns, O Evangelho Segundo o Espiritismo, o Céu e o Inferno e A Gênesis codificadas por Allan Kardec.

Em uma sociedade nascente que se buscava moderna, que se pauta pela ordem e pelo progresso, nada além do que pudesse ser comprovado - seguindo as leis da física, matemática, química, ou seja, de forma empírica e positivista - seria aceito como prática verdadeira dentro de conceitos tão rígidos. Deste modo, começa a tomar forma a até então ciência espírita, excluindo tudo o que era místico, tentando tornar ideia da reencarnação do espírito, em algo palpável aos olhos e ouvidos de incrédulos cientistas.

\section{Procedimentos de controle da produção discursiva}

Podemos afirmar que nossa sociedade é a sociedade do discurso. Nós produzimos e 
somos produzidos nele e por ele. Observamos a materialização do discurso nos nossos corpos, em livros, em fotografias, em pinturas, na dança, na arquitetura. Ao se materializar, ele ganha significado, sentidos e exerce uma relação de força e poder.

Nós somos os produtores dos discursos, mas o que interessa a Foucault pós 1970 é compreender a relação de poder existente entre o sujeito e o discurso (FERNANDES, 2012).

Em toda sociedade a produção do discurso é ao mesmo tempo controlada, selecionada, organizada e redistribuída por certo número de procedimentos que têm por função conjurar seus poderes e perigos, dominar seu acontecimento aleatório, esquivar sua pesada e temível materialidade. (FOUCAULT, 1996, p 8-9)

Foucault nos ensina que existem três efeitos causados pelos mecanismos discursivos, que seriam a exclusão, sujeição e rarefação do sujeito. Esses efeitos são decorrências dos procedimentos responsáveis pelo controle dos discursos e da sua materialização.

Eles são externos e internos. Fazem parte do primeiro, a interdição, a segregação e a vontade de verdade. Ficando determinado o que é proibido, pois, "não se tem o direito de dizer tudo, [...] não se pode falar tudo em qualquer circunstância, [...] qualquer um não pode falar qualquer coisa" (ibdem, p. 09). Ficam delimitados os espaços onde cada sujeito poderá circular ou não, falar ou não. A censura existe e é exercida ao se definir o que é normal e o que é patológico.

Os rituais da palavra separam em quem pode ou não pode falar; a vontade de verdade opõe em verdadeiro e falso o que é dito. Um exemplo simples são as palestras públicas que ocorrem nos centros espíritas, algo que dura em torno de uma hora, onde ape- nas o palestrante tem o direito de falar e expor suas ideias, e não é possível questionar.

Nesse momento, o palestrante, que é um intelectual ou médium espírita, é responsável por informar o que é tido como verdadeiro, pois, já foi julgado, anteriormente, pela direção da casa espírita, bem como pelo seu currículo e histórico de vivência da doutrina espírita, que é digno de expor suas ideias. A palavra é ritualizada nas palestras públicas, nos cursos oferecidos, bem como nas leituras recomendadas, não é qualquer sujeito que tem a autoridade de indicar leituras sobre determinado tema.

As articulações realizadas pelo espiritismo na tentativa de construir um saber religioso e científico agem via produções discursivas que produzem verdades, ao passo que desqualificam ou requalificam outros saberes a partir da reinterpretação, ou no caso, via comentário.

Os Procedimentos internos de controle, segundo Foucault, são exercidos pelo próprio discurso via comentário, que se repetem e comentam. É um processo onde "muitos textos maiores se confundem e desaparecem" (FOUCAULT, 1996, p. 23). Ocorrendo a substituição por comentários, que tomam o lugar dos originais. Tais comentários não são estáveis ou absolutos, assim são os jogos discursivos.

Não há, de um lado, a categoria dada uma vez por todas, dos discursos fundamentais ou criadores; e, de outro, a massa daqueles que repetem, glosam e comentam. Muitos textos maiores se confundem e desaparecem, e, por vezes, comentários vêm tomar o primeiro lugar. Mas embora seus pontos de aplicação possam mudar, a função permanece; e o princípio de um deslocamento encontra-se sem cessar reposto em jogo (FOUCAULT, p. 23).

O comentário é o princípio interno que permite a classificação e a categorização dos 
discursos. Foucault apresenta os discursos religiosos e jurídicos como exemplos do comentário.

Os discursos que "se dizem" no correr dos dias e das trocas, e que passam com o ato mesmo que os pronunciou; e os discursos que estão na origem de certo número de atos novos de fala que os retomam, os transformam ou falam deles, ou seja, os discursos que, indefinidamente, para além de sua formulação, são ditos, permanecem ditos e estão ainda por dizer (1996, Ibid., p. 22).

O discurso controla o próprio discurso. Observamos o comentário como mecanismo de controle atuando na constituição do espiritismo enquanto doutrina e disciplina. Analisando um dos livros do Pentateuco espírita fica claro uma reatualização dos preceitos cristãos encontrados na Bíblia.

Assim, o espiritismo seria uma atualização do comentário constituinte. Para muitos, o espiritismo é a terceira revelação, ou na própria interpretação de doutrinadores, o espiritismo seria a chave de leitura que faltava para compreender definitivamente o cristianismo, expondo "enfim o que estava articulado silenciosamente no texto primeiro" (Foucault, 1996, p. 25).

A lei do Antigo Testamento teve em Moisés a sua personificação; a do Novo Testamento tem-na no Cristo. O Espiritismo é a terceira revelação da Lei de Deus, mas não tem a personificá-la nenhuma individualidade, porque é fruto do ensino dado, não por um homem, sim pelos Espíritos, que são as vozes do Céu, em todos os pontos da Terra, com o concurso de uma multidão inumerável de intermediários. É, de certa maneira, um ser coletivo, formado pelo conjunto dos seres do mundo espiritual, cada um dos quais traz o tributo de suas luzes aos homens, para lhes tornar conhecido esse mundo e a sorte que os espera. Da mesma maneira que disse o Cristo: "Eu não venho destruir a lei, mas dar-lhe cumprimento". Também diz o Espi- ritismo: "Eu não venho destruir a lei cristã, mas dar-lhe cumprimento". Ele nada ensina contrário ao ensinamento do Cristo, mas o desenvolve, completa e explica, em termos claros para todos, o que foi dito sob forma alegórica. Ele vem cumprir, na época predita, o que o Cristo anunciou, e preparar o cumprimento das coisas futuras. Ele é, portanto, obra do Cristo, que o preside, assim como preside ao que igualmente anunciou: a regeneração que se opera e que prepara o Reino de Deus sobre a Terra. (O Evangelho Segundo o Espiritismo, 2013, p. 44)

Podemos observar essa reatualização em "O Evangelho Segundo o Espiritismo", no qual encontramos uma ressignificação dos evangelhos bíblicos, além de algumas reflexões incorporadas ao "novo Texto" do próprio Kardec e de alguns santos católicos.

Essa ideia pode ser observada nos discursos colhidos durante as nossas entrevistas, já que a fala desses sujeitos podem ser compreendidas como um comentário, mas não fundante. Um comentário que não se fixa, mas é fruto do comentário anterior produzido pelos espíritos que se comunicaram com Kardec. Pedro ${ }^{2}$ nos informa: "na verdade não é religião né, e não é kardecista, na verdade é a doutrina espírita. Porque a doutrina é dos espíritos e não de Kardec, Kardec só codificou".

Ao ser reinterpretada por Kardec, a doutrina passa a agregar novas concepções, sempre atreladas à ciência, numa tentativa de desviar as críticas da igreja católica, ao mesmo tempo e que busca o apoio do campo científico. Uma estratégia em busca de reconhecimento do campo religioso e científico francês acabou desagradando os dois, comprando brigas, despertando a curiosi-

2 Entrevista concedida por Pedro Paulo. Entrevista I. [jan. 2019]. Entrevistador: Francisco Jomário Pereira. Acervo pessoal. Campina Grande, 2019. 1 arquivo .mp3 (70 min.) 
dade de muitos e acabou ganhando evidência e seguidores.

Mas Pedro tem mais a nos informar sobre a sua concepção do espiritismo:

Doutrina é porque ela envolve três vertentes, a religiosa porque trabalha com o evangelho, mas isso não transforma ela em religião porque ela não tem dogma. Ela é ciência porque ela trabalha na pesquisa, principalmente através de mediunidade, ciência religião... ai meu Deus... e... e filosofia, porque ela também segue algumas vertentes filosóficas. Inclusive o evangelho é uma vertente filosófica.

Observamos que Pedro sempre volta ao evangelho, mesmo afirmando que a doutrina espírita não é uma religião. 0 espiritismo demonstra absorver e adotar alguns aspectos específicos do cristianismo (religião), seja ele católico ou protestante. Faz isso de forma exemplar, pois, seus seguidores compram a ideia de que a doutrina não é religião.

Essa lógica é reforçada pelas posições tomadas diante aos dogmas cristãos, especialmente em se tratando da ressurreição de Cristo; a doutrina nega a ressureição, mas defende a reencarnação. Assim sendo, não se pode enquadrar o espiritismo enquanto religião cristã, ao menos seguindo a lógica católica. No entanto, o espiritismo se reconhece enquanto cristão, especialmente em suas práticas de assistencialismo e caridade - característica principal na atualidade -, mas o assistencialismo prestado não é visto de forma negativa, pelo contrário, é sempre encarado com bons olhos.

Nosso entrevistado Mateus ${ }^{3}$ nos mostra, ou melhor, nos ensina que o espiritismo não seria puramente a atualização de uma reli-

3 Entrevista concedida por Mateus Lucas. Entrevista II. [fev. 2019]. Entrevistador: Francisco Jomário Pereira. Acervo pessoal. Campina Grande, 2019. 1 arquivo .mp3 (50 min.) gião, mas sim de uma ciência com fins morais. Ele reproduz o que leu e ouviu durante anos em suas idas aos centros espíritas.

Pesquisador: Eu fico na dúvida... é doutrina ou é religião?

Mateus: É... o Alan Kardec, ele... ele... na verdade ele consegue... ele... como ele era um pesquisador, e ele era cético, era um físico, ele atribui ao espiritismo como uma doutrina, uma ciência. Enquanto que a nossa ciência convencional estuda o princípio material, o espiritismo ele também é uma ciência mas ele estuda o princípio espiritual. Não que ele venha trazer novas leis, mas ele apenas vai se debruçar pra entender que leis é essa que a gente não tava... não tá compreendendo. E como tudo começou com as mesas girantes, né?! Como é que uma mesa... como é que uma cadeira, começa a voar do nada. Então ele começou a falar com a cadeira, e fazia... ascendia as luzes, e... enfim... é uma história bem interessante. E ele de... ele começou a dizer, não... porque isso... não tem que ter alguma coisa, até que... ele foi realmente, e os próprios espíritos disseram, não a gente se submete a sua pesquisa, o que você quiser... mas aí a gente precisa que você, realmente catalogue e mostre que isso não é uma... uma.. fantasia, isso é uma realidade. Aí pronto, aí... o que é que acontece... só que ele é uma ciência, que tem uma filosofia, a partir dessas perguntas, a ciência responde, e o seu resultado, que é a moral. Então ela pode sim, você pode dizer que o espiritismo é uma religião, e pode dizer que ela é uma ciência, porque o tripé dela, ciência, filosofia, com fins morais, ou seja, religiosos.

Na tentativa de reinterpretação, observa-se a apropriação de discursos, que por muito tempo foram tidos como antagônicos, o científico, o filosófico e o religioso. Cremos que essa junção ocorra no espiritismo na busca do respaldo da sociedade, além da tentativa de se distinguir do catolicismo 
sem deixar de lado algumas características importantes do cristianismo.

Justamente por ser composta por três concepções distintas em seu cerne, é que houve as disputas internas no Brasil durante a constituição de diretrizes gerais, provocando a existência de místicos e científicos. Acabou se impondo a característica religiosa ou mística por parte da FEB, tornando o nosso espiritismo distinto do francês, mas vale ressaltar que em momentos oportunos o discurso científico é acionado, especialmente quando se discute os limites externos da religião, basta observar o que nos relatou Mateus.

Entre os mais reconhecidos espíritas, Bezerra de Menezes, o Kardec brasileiro, reforça que o "espiritismo não é ciência como apregoam os que procuram nos fenômenos [...] antes o maravilhoso do que ensinos de salvação. Se o Espiritismo fosse ciência, seria invenção ou descoberta dos homens como tem sido todas as que são conhecidas até hoje". (O Reformador, 15/08/1896).

A fala de Bezerra se choca com a posição adotada pela FEB no sentido que, a instituição indicava os livros dos médiuns e dos espíritos como obras básicas e necessárias, mesmas obras que o grupo científico adotava, relegando as demais ao esquecimento. Essas duas obras são as bases do cientificismo kardeckiano. Contudo Bezerra busca dirimir o problema ao afirmar que "espiritismo é ciência: religião científica" (O Reformador, 15/08/1896).

Tendemos a concordar em partes, já que o que temos observado mostra mais que uma simples predominância do lado religioso, ao menos entre nossos entrevistados, até mesmo quando tratam dos assuntos estudo ou mediunidade. Estes são sempre carregados de conotações religiosas remanescentes do catolicismo, guiadas por leituras do evangelho e calcadas na prática da caridade.

Pedro: A doutrina é muito, ela é de ação. É isso que eu entendo que a doutrina passa. De você agir no bem, de você trabalhar no bem, trabalhar o evangelho, na caridade, na assistência... aos outros.

Mateus coloca os livros indicados pela FEB como base de leitura, mas insiste em demonstrar como a literatura assessória influencia em sua concepção ao ser questionado sobre a doutrina, se é ou não religião.

Mateus: É... os livros que... que me ajudaram muito a entender, foi a coleção de André Luiz, né... , Nosso Lar, Os Mensageiros, Missionários da Luz, aquela... aquela sequência de estudos do próprio André Luiz né, psicografia de Chico Xavier, também... alguns livros de... de... da... A Codificação, né... questão do Livro dos Espíritos... o Livros dos Médiuns... né... a questão do Céu ou Inferno, que também é muito bacana, teve outros livros acessórios, mas se você perguntar: (nome do sujeito), o que realmente fundamentou pra que você pudesse ter uma opinião com base nisso, então... eu diria que a codificação, né...tanto a codificação como as obras de André Luiz.

Podemos observar o comentário agindo, isso é perceptível nos discursos escritos, como verbalizados. Essa prática é perceptível dentro do próprio catolicismo, pois, observa-se o catolicismo romano e o dito catolicismo brasileiro, que têm suas particularidades. Da mesma forma, se institui o espiritismo brasileiro, que não deixa de ser uma interpretação do espiritismo francês e uma reinterpretação do catolicismo brasileiro.

Os outros dois procedimentos da nossa análise são, autor e disciplina. Sobre o autor, Foucault sugere um apagamento do sujeito, ou seja, o autor não seria um indivíduo, o autor é um ser exterior e anterior ao próprio texto.

0 autor é uma função discursiva, bem como um dispositivo de controle de sentidos 
que regula a ordem do discurso. "0 autor, não entendido, é claro, como o indivíduo falante que pronunciou ou escreveu um texto, mas o autor como princípio de agrupamento do discurso, como unidade e origem de suas significações, como foco de sua coerência". (Foucault, 1996, p. 26).

0 princípio da autoria engloba as relações que reordenaram e constituíram signos e objetos que fazem parte da construção do discurso, sendo tais relações internas ou externas, ocorrendo conscientes ou inconscientes.

Por fim, temos as disciplinas, "princípio relativo e móvel. Princípio que permite construir, mas conforme um jogo restrito" (FOUCAULT, 1996, p. 30). Jogo que determina as proposições que serão consideradas verdadeiras. "Uma disciplina, a partir de seus princípios de regularidade, delimita o discurso em face do que, em seu interior, constitui verdade (FERNANDES, 2012, p. 51-50).

Um terceiro mecanismo que permite controlar os discursos estaria relacionado com o funcionamento, a imposição aos indivíduos da pronúncia "correta", fazendo com que se adequem à ordem do discurso, "as imposições de regras aos sujeitos implicam em impor determinações dos papéis dos mesmos na produção dos discursos" (SILVA \& MACHADO JÚNIOR, 2014, s/p).

Existem ainda as sociedades de discurso, que são responsáveis por um jogo de não permutabilidade/troca de discursos específicos para com agentes externos. Tendo por finalidade "conservar ou produzir discursos, mas para fazê-los circular em um espaço fechado, distribuí-los somente segundo regras estritas, sem que seus detentores sejam despossuídos por essa distribuição" (1996, Ibid., p. 30). Podemos chamar de estratégia de autopreservação.

Já as Doutrinas:

Constituem o inverso de uma "sociedade do discurso": nesta, o número de indivíduos que falam, mesmo se não fosse fixado, tendia a ser limitado; e só entre eles o discurso podia circular e ser transmitido. A doutrina, pelo contrário, tende a difundir-se; e é pela partilha de um só e mesmo conjunto de discursos que indivíduos, tão numerosos quanto se queiram imaginar, definem sua pertença recíproca. Aparentemente, a única condição requerida é o reconhecimento das mesmas verdades e a aceitação de uma certa regra [...] de conformidade com os discursos validados. (FOUCAULT, 1996, p. 41-42)

A relação existente entre doutrina e sujeitos é de assujeitamento, ou seja, ocorre sujeição dos sujeitos ao discurso, na mesma proporção que os discursos aos indivíduos. Uma relação de poder, onde as partes envolvidas se relacionam de modo dialético. Analisamos uma doutrina especifica em nosso trabalho, a espirita, e como toda e qualquer doutrina, vislumbra propagarse e expandir-se. No caso estudado, essa busca se concretiza via discursos escritos na codificação de Kardec e os livros ditos como acessórios, publicações de Chico Xavier e Divaldo Franco, por exemplo, bem como recorrendo ao carisma de seus líderes, sempre baseados em um ensino que reproduz os modos acadêmicos. Este esse fenômeno pode ser observado nas palestras públicas. Que funcionam como aulas, ou em cursos semanalmente ofertados nas instituições espíritas.

Ideia de que aos poucos as religiões do mundo irão agregar os conceitos fundamentais do Espiritismo. E que as religiões ficarão naturalmente tão parecidas, que não se fará mais a distinção entre uma e outra. Pouco importará a qual religião se siga. Haverá uma harmonia mundial em relação a conceitos sobre vida e espiritualidade. Todos unidos em concordância, em prol do Bem Universal. (KARDEC, A GÊNESE, 2013, item 17, do capítulo 18) 
Kardec (2013), supostamente orientado pelos espíritos, chegou a afirmar que no futuro, a doutrina espírita seria universal e que todas as demais religiões iriam adotá-la. Cumpre à capacidade intelectual um papel preponderante dentro do espiritismo, uma das máximas da doutrina é diretamente relacionada à capacidade de aprender. "Espíritas!, amai-vos, eis o primeiro ensinamento. Instruí-vos, eis o segundo". (KARDEC, 0 Evangelho Segundo o Espiritismo, 2013, Cap. VI, item 5).

O espiritismo seguiu por um viés diferenciado do pensado por Kardec, que o idealizou influenciado pelo pensamento da época. Como a laicidade, o progresso e o espírito científico, atraindo cientistas e literatos. Assim, o espiritismo surge com a missão de unir três campos aparentemente opostos, a Religião, a Filosofia e a Ciência:

Kardec, que criou uma religião altamente relacionada com os ideais de sua época: a laicidade, o progresso e o espírito científico [...] Nesse sentido, o espiritismo anunciavase como uma religião natural, o que originou uma tensa e não resolvida relação entre demonstração experimental e revelação, que significa que seu prestígio era dependente da simpatia da comunidade intelectual pelo fenômeno (LEWGOY, 2008, p. 86, grifos nossos).

Com relação ao "espiritismo brasileiro", percebe-se uma substancial mudança, pois:

No caso brasileiro, houve dois deslocamentos importantes em relação ao cientificismo kardequiano: o deslocamento da ênfase na mensagem para a ênfase no carisma do médium e o deslocamento da comunicação espírita em três indivíduos desconhecidos num mesmo espaço mediúnico impessoal para a mediação relacional entre seres já ligados por nexos anteriores, geralmente familiares. Comparando a inserção do espiritismo nas histórias francesa e brasileira Aubrée e Laplantine (1990) mostraram que, comparada à França do século XIX, na sessão espírita no Brasil do século XX predominou um espaço familiar antes que um espaço impessoal. Por isso, as mães e mulheres, figuras centrais na mediação familiar, são tão importantes no desenrolar das sessões (LEWGOY, 2008, p.86).

0 formato adotado se deve, em grande medida, ao seu enxerto nos lares católicos; não o catolicismo romano, mas o próprio catolicismo brasileiro, uma derivação do romano. Com isso, pode-se afirmar que o nosso modo de ser espírita tem fortes influências do catolicismo brasileiro. Ao ser instalado nesses lares, onde perseverava o ethos católico, os discursos reinscritos puderam se solidificar e perseverar, o contexto social e religioso foi um forte influenciador para o afloramento do espiritismo no Brasil.

Fernandes (2008) chama atenção para os conceitos ressignificados e construídos pelo espiritismo, mostrando a busca pela produção de significados via discursos baseados em conceitos filosóficos e científicos, estratégia para legitimar e firmar proposta doutrinária. Assim,

O espiritismo acredita que ciência, filosofia e religião devam andar juntas. Sabemos que o atual paradigma científico não aceita tal visão, tendo em vista o pano de fundo histórico em que se formou a ciência moderna, em suas lutas contra a tradição, que era grandemente representada pela religião em suas mais variadas facetas (FERNANDES, 2008. p. 08).

Tendo a compreensão de que os conceitos espíritas de ciência e filosofia são pensados a partir da própria doutrina, que tentou aglutinar, de forma sistemática, três formas distintas de pensar a realidade, devemos observar atentamente que essa busca foi fruto do contexto social, que acabou sendo inscrito e retraduzido pela vontade da verdade, bem como pela constituição de uma 
instituição que restringe e unge os sujeitos dignos de externalizar a verdade espírita.

\section{Considerações}

Aqui no Brasil tudo é muito religioso, né? (Simão ${ }^{4}$.

Observa-se que, por décadas o espiritismo buscou se definir enquanto religião, ciência e filosofia. Podemos afirmar que ao ser transladado para o Brasil, o espiritismo ganhou uma nova roupagem. Lewgoy (2008) assevera que o espiritismo ganhou novo formato, aparentando o mesmo processo pelo qual passou o Catolicismo ao se tornar um catolicismo popular, distante do Romano, onde sofreu hibridismo e a influência dos negros e dos índios.

Assim, todo o processo de constituição da doutrina em terras brasileiras passa e perpassa por embates, tentativas de ganhar forma, acessando discursos específicos que se confrontam, surgindo, assim, as dissidências e a criação de novos grupos que adotam o discurso que melhor lhe convém ou que consideram mais adequado.

Podemos observar o processo de formação discursiva a partir da análise do discurso espírita brasileiro. Sabemos quais as influências incidiram no estabelecimento da doutrina, quais verdades foram tomadas como lastro doutrinário, como essas verdades são ensinadas e a forma que elas tomam. 0 Espiritismo brasileiro é fruto de um mecanismo de cerceamento e controle dos sentidos.

\section{Referências Bibliográficas}

ARRIBAS, Célia da Graça. Afinal, espiritismo é

4 Entrevista concedida por Simão Silva. Entrevista III. [fev. 2019]. Entrevistador: Francisco Jomário Pereira. Campina Grande, 2019. 1 arquivo .mp3 (100 min.) religião? A doutrina espírita na formação da diversidade religiosa brasileira. São Paulo: Alameda, 2010.

Uma sociologia histórica do espiritismo. Anais do III encontro nacional do gt história das religiões e das religiosidades - anpuh -Questões teórico-metodológicas no estudo das religiões e religiosidades. IN: Revista Brasileira de História das Religiões. Maringá (PR) v. III, n.9, jan/2011. ISSN 1983-2859.

No Princípio Era Verbo. Espíritas e Espiritismos na Modernidade Religiosa Brasileira. Tese de Doutorado em Sociologia no Programa de Pós Graduação em Sociologia da Universidade De São Paulo. São Paulo. 2014.

FERNANDES; Claudimar Alves. Discurso e sujeito em Michel Foucault. Intermeios. São Paulo. 2012.

FOUCUALT, Michel. História da Sexualidade. Vol. 1, 2014. Vol. 2, 2014. Vol. 3, 2017. Paz e Terra. Rio de Janeiro/São Paulo.

A Microfísica do Poder. Paz e Terra. 2014.

Vigiar e Punir. Petrópolis: Vozes, 2014

Os Anormais. Curso no Collège de France (1974-1974). Martins Fontes. São Paulo. 2001.

De l'amitié comme mode de vie. Entrevista de Michel Foucault a R. de Ceccaty, J. Danet e J. le Bitoux, publicada no jornal Gai Pied, no 25, abril de 1981, pp. 38-39. Tradução de wanderson flor do nascimento.

GUIUMBELLI, Emerson. A presença do religioso no espaço público: modalidades no Brasil. Relig. soc. vol.28 no. 2 Rio de Janeiro 2008.

Heresia, doença, crime ou religião: o Espiritismo no discurso de médicos e cientistas sociais. Rev. Antropol. vol.40 n.2 São Paulo 1997.

GREGOLIN, Maria do Rosário. Foucault e Pêcheux na análise do discurso- diálogos \& duelos. São Carlos. Editora Clara Luz. 2006.

LEWGOY, Bernardo. A transnacionalização do espiritismo kardecista brasileiro: uma discussão inicia. Relig. soc. vol.28 no.1 Rio de Janeiro July 2008.

Chico Xavier e a Cultura Brasi- 
leira. Rev. Antropol. vol.44 no.1 São Paulo 2001. Etnografia da leitura num grupo de estudos espírita. Horiz. antropol. vol.10 no.22 Porto Alegre July/Dec. 2004.

Os Espíritas e as letras: um estudo antropológico sobre cultura escrita e oralidade no espiritismo kardecista. Tese de Doutorado apresentada ao Programa de Pós Graduação em Antropologia da Universidade de São Paulo. São Paulo. 2000.

NOGUEIRA, Conceição. Análise do discurso. Em L. Almeida e E. Fernandes (Edts), Métodos e técnicas de avaliação: novos contributos para a pratica e investigação. Braga: CEEP

SILVA \& Machado Júnior, Revista Eletrônica História em Reflexão: Vol. 8 n. 16 - UFGD - Dourados, jul/dez - 2014. O discurso em Michel Foucault - Por Giuslane Francisca da Silva \& Sérgio da Silva Machado Júnior.

\section{Obras analisadas}

ANDRÉ LUIS (Espírito). Sexo e Destino. Psicografado por Waldo Vieira e Francisco Cândido Xavier. Editora FEB. Brasília. S/D.

EMMANUEL (Espírito). Vida e Sexo. Psicografado por Francisco Cândido Xavier. Editora FEB. Brasília. 2016.

FEB, Federação Espírita Brasileira. < http:// www.febeditora.com.br/quem-somos/> acessado em 03 de janeiro de 2019.

Mediunidade: Tipos de psicografia. <https://www.febnet.org.br/wp-content/
uploads/2012/06/Modulo-2-Tema-5-Psicofonia-e-psicografia.pdf.> Acessado em 03 de janeiro de 2019.

FEBP, Federação Espírita Paraibana < http:// www.fepb.org.br/estrutura-funcional/ centrosespiritas / ? cidade=Campina+Grande+PB\&bairro=Todos+os+bairros $>$. Acessado em: 20 de março de 2019.

KARDEC, Allan. O Evangelho Segundo o Espiritismo. Editora Petit. 1997.

O Livro dos Espíritos. Editora Petit.

1997.

1997.

O Livro dos Médiuns. Editora Petit.

LOPES, Luiz Fernando (org). Amor e Sexualidade: A conquista da Alma. Editora Leal. Salvador. 2018.

dor. 2016

Sexo e Consciência. Editora Leal. Salva-

MANOEL (Espírito). Sexo e Obsessão. Psicografado por Divaldo Pereira Franco. Editora Leal. Salvador. 2002.

MENEZES, Bezerra. União dos spiritas. Revista O Reformador. Rio de Janeiro. V. 14. N. 32. Agosto. 1896.

SAEGUSA, Claudia (org). Divaldo Franco Responde. Vol. 2. InteLítera, São Paulo. 2013.

Recebido em: 15/05/2020

Aprovado em: 14/07/2020 